\begin{tabular}{|c|c|c|}
\hline \multirow{2}{*}{$\begin{array}{r}\text { Case Reports in } \\
\text { Gastroenterology }\end{array}$} & \multicolumn{2}{|c|}{ Case Rep Gastroenterol 2016;10:775-780 } \\
\hline & $\begin{array}{l}\text { DOI: 10.1159/000448879 } \\
\text { Published online: December 20, } 2016\end{array}$ & $\begin{array}{l}\text { (C) } 2016 \text { The Author(s) } \\
\text { Published by S. Karger AG, Basel } \\
\text { www.karger.com/crg }\end{array}$ \\
\hline
\end{tabular}

\title{
Spontaneous Isolated Superior Mesenteric Artery Dissection
}

\author{
Anand Nath ${ }^{a} \quad$ Sayali Yewale ${ }^{b} \quad$ Mohammad Kousha $^{c}$ \\ ${ }^{\mathrm{a}}$ Department of Internal Medicine, MedStar Washington Hospital Center, \\ Washington, DC, USA; ${ }^{b}$ Advanced Pediatric Imaging Lab, Children's National Medical \\ Center, Washington, DC, USA; ${ }^{\circ}$ Department of Pulmonary/Critical Care Medicine, \\ Temple University Hospital, Philadelphia, PA, USA
}

\section{Keywords}

Superior mesenteric artery · Spontaneous dissection · Computed tomography of the abdomen

\section{Abstract}

A true isolated superior mesenteric artery (SMA) dissection is a rare occurrence. The increasing use of diagnostic imaging studies has resulted in this rare disease being more recognized. A 68-year-old Caucasian female presented with sharp upper abdominal pain. Computed tomography $(\mathrm{CT})$ of the abdomen showed dissection with thrombosis in the proximal SMA. Conservative management with bowel rest, blood pressure control, and anticoagulation relieved her symptoms. Follow-up CT showed stable dissection. Physicians should consider the diagnosis of isolated spontaneous SMA dissection after excluding more common causes. The optimal management pathway has not been firmly established. Conservative management with anticoagulation appears to be a safe first-line therapy in selected patients.

(C) 2016 The Author(s)

Published by S. Karger AG, Basel

\section{Introduction}

The superior mesenteric artery (SMA) is the second of the three major anterior branches of the abdominal aorta and arises from the anterior surface of the abdominal aorta, just 


\section{Case Reports in \\ Gastroenterology}

Case Rep Gastroenterol 2016;10:775-780

DOI: $10.1159 / 000448879$

(c) 2016 The Author(s). Published by S. Karger AG, Basel www.karger.com/crg

Nath et al.: Spontaneous Isolated Superior Mesenteric Artery Dissection

inferior to the origin of the celiac trunk at the level of the L1 vertebra. It supplies blood to the organs of the midgut and intestine from the lower part of the duodenum through two-thirds of the transverse colon, and to other abdominal viscera including the pancreas [1]. Arterial dissection is defined as the cleavage of the arterial wall by an intramural hematoma. Dissection of the SMA is often seen as an extension of aortic dissection. A true isolated SMA dissection is a rare occurrence. This was first described in 1947 by Bauersfeld [2], but few cases have been reported in the literature since then [3-10]. However, the increasing use of diagnostic imaging studies in the management of patients with acute abdominal pain has resulted in this rare disease having receied more attention recently. The initial symptom in most patients is acute epigastric pain due to intestinal ischemia, although some asymptomatic cases can be detected as incidental finding on imaging. Chronic or subacute dissection may present with additional symptoms such as postprandial abdominal pain and weight loss [11, 12]. We hereby present and discuss the case of an isolated spontaneous dissection of SMA at our institution.

\section{Case}

A 68-year-old Caucasian female presented with a 2-week history of progressive upper abdominal discomfort which had noticeably worsened in the last 5 days. She first presented to her primary care provider and then came to the emergency department due to persistent pain. The pain was constant, sharp, 9/10 in severity, radiating to her back, slightly worse after eating, and not relieved with over-the-counter pain medications. She endorsed constipation and a mild weight loss but denied any other symptoms.

Her past medical history was significant for hypertension, subclinical hypothyroidism, osteopenia, and cervical spondylosis. Her previous surgeries included small adenomatous colonic polyp removal during a screening colonoscopy, tubal ligation, breast lumpectomy, appendectomy, and an abdominal surgery after swallowing a toothpick 40 years ago. She denied any medications other than lisinopril and over-the-counter ibuprofen. She admitted to active tobacco use (about 10 pack-year), but denied alcohol or illicit drug abuse.

On physical examination, she was tachycardic with a pulse rate of $109 \mathrm{bpm}$ and hypertensive with a blood pressure of $160 / 110 \mathrm{~mm} \mathrm{Hg}$. Other vital signs were in the normal range. Her body mass index was 24 . She had moderate epigastric and left upper quadrant tenderness on palpation with mild rebound and voluntary guarding on abdominal examination. Bowel sounds were present. No masses were felt, and there was no distention. The rest of the physical examination was unremarkable.

Initial laboratory tests, including blood counts, metabolic panel, liver function test, amylase, lipase and lactic acid, were within the normal range. Ultrasound of the right upper quadrant was normal. A computed tomography (CT) scan of the abdomen was done with intravenous contrast showing an area of dissection with thrombosis in the proximal SMA beginning just beyond its origin for a length of about $7 \mathrm{~cm}$ (Fig. 1, Fig. 2, Fig. 3).

After careful consideration, no surgical intervention was done, and she was managed conservatively with bowel rest, blood pressure control, and anticoagulation with IV heparin. She was monitored in the Intensive Care Unit. Her symptoms improved with conservative measures. The rest of her hospital course was uncomplicated and the patient was discharged home on warfarin in addition to her outpatient antihypertensive medications. 
She was followed up in the surgery clinic at 2 weeks and reported that her symptoms had completely resolved. A follow-up CT showed stable dissection. She had multiple followup CT scans which showed a gradual decrease in the size of the dissection.

\section{Discussion}

Isolated SMA usually occurs after a tear in the intima or primary hemorrhage in the media (due to rupture of the vasa vasorum) where blood collects between the medial and adventitial layers. Blood collection extends over a variable distance.

Several causal factors have been postulated, including congenital connective tissue disorders, fibromuscular dysplasia, cystic medial necrosis, trauma, as well as hypertension, although strong association needs to be established [1,3]. Based on a retrospective study of 51 patients, Park et al. [4] suggested that it may less likely be the result of hypertension or connective tissue disease but more likely due to hemodynamic force caused by convex curvature.

Given the rarity of the condition, its natural course is not clearly known. In a retrospective study of 46 patients by Park et al. [5], 15.2\% had complete remodeling of dissection on follow-up CT angiograms, while $41.3 \%$ had a decrease in the false lumen size, and $43.5 \%$ had no change. None of the patients showed dissection progression. In another study of 24 patients by Park et al. [6], complete remodeling, partial remodeling, no change, and dissection progression were seen in $25,17,38$, and $20 \%$ respectively.

Treatment approaches include conservative management with anticoagulation and blood pressure control, percutaneous endovascular interventions such as stent placements [7], intralesional thrombolytic therapy or embolotherapy, and surgical interventions such as artery ligation, endoaneurysmorraphy, aortomesenteric bypass, or laparotomic resection. A treatment algorithm has been suggested by some authors $[9,10,13,14]$. However, optimal management has not been firmly established. In asymptomatic patients with incidental findings or in symptomatic patients with no evidence of bowel infarction, bleeding, or aneurysmal changes, with good flow on the angiogram, conservative treatment may be the first choice. Endovascular treatment should be performed in the case of dissection progression, increasing size of the aneurysmal dilatation of the SMA, luminal thrombosis, or persistent symptoms despite anticoagulation. Emergency laparotomy with surgical repair may be reserved for patients in whom low blood flow with bowel necrosis or artery rupture is suspected.

Isolated, spontaneous dissection of the SMA is a rare disease that has recently become more recognized with the increasing use of diagnostic imaging studies. This diagnosis should be considered when other more common causes of acute abdominal pain have been excluded. Currently, there is no optimal management that has been firmly established. Based on the individual presentation, treatment approaches include conservative management, percutaneous endovascular interventions, or surgical treatment. 


\section{Case Reports in \\ Gastroenterology}

\begin{tabular}{l|l}
\hline DOI: $10.1159 / 000448879$ & (C) 2016 The Author(s). Published by S. Karger AG, Basel
\end{tabular} www.karger.com/crg

Nath et al.: Spontaneous Isolated Superior Mesenteric Artery Dissection

\section{Statement of Ethics}

There are no ethical conflicts to declare. Informed consent was obtained from the patient over the phone in the presence of 2 witnesses. Approval for the study was obtained from the MedStar Research Institute (Hyattsville, MD, USA) - Office of Research Integrity (ORI) on September 15, 2016.

\section{Disclosure Statement}

The authors did not receive any sponsorship or funding and do not have any conflicts of interest related to the case.

\section{References}

1 Gray H, Lewis WH: Anatomy of the Human Body, ed 20. Philadelphia, Lea \& Febiger, 1918. Bartleby.com, 2000. www.bartleby.com/107/ (accessed June 30, 2016).

2 Bauersfeld SR: Dissecting aneurysm of the aorta: a presentation of 15 cases and a review of the recent literature. Ann Intern Med 1947;26:873-889.

-3 Sheldon PJ, Esther JB, Sheldon EL, et al: Spontaneous dissection of the superior mesenteric artery. Cardiovasc Intervent Radiol 2001;24:329-331.

4 Jia Z, Zhang X, Wang W, et al: Spontaneous isolated superior mesenteric artery dissection: genetic heterogeneity of chromosome locus 5q13-14 in 2 male familial cases. Ann Vasc Surg 2015;29:1019. Park YJ, Park CW, Park KB, et al: Inference from clinical and fluid dynamic studies about underlying cause of spontaneous isolated superior mesenteric artery dissection. J Vasc Surg 2011;53:80-86. Park YJ, Park KB, Kim DI, et al: Natural history of spontaneous isolated superior mesenteric artery dissection derived from follow-up after conservative treatment. J Vasc Surg 2011;54:1727-1733. Park UJ, Kim HT, Cho WH, et al: Clinical course and angiographic changes of spontaneous isolated superior mesenteric artery dissection after conservative treatment. Surg Today 2014;44:2092-2097.

-8 Mitsuoka H, Nakai M, Terai Y, et al: Retrograde stent placement for symptomatic spontaneous isolated dissection of the superior mesenteric artery. Ann Vasc Surg 2016;S0890-5096(16)30343-0.

$\$ 9$ Subhas G, Gupta A, Nawalany M, et al: Spontaneous isolated superior mesenteric artery dissection: a case report and literature review with management algorithm. Ann Vasc Surg 2009;23:788-798.

10 Katsura M, Mototake H, Takara H, et al: Management of spontaneous isolated dissection of the superior mesenteric artery: case report and literature review. World J Emerg Surg 2011;6:16.

11 Javerliat I, Becquemin JP, d'Audiffret A: Spontaneous isolated dissection of the superior mesenteric artery. Eur J Vasc Endovasc Surg 2003;25:180-184.

12 Aydin S, Ergun E, Fatihoglu E, Durhan G, Kosar PN: Spontaneous isolated celiac artery and superior mesenteric artery dissections: a rare case. Pol J Radiol 2015;80:470-472.

13 Takahashi B, Nakayama Y, Shiroma S, et al: Three case reports of spontaneous isolated dissection of the superior mesenteric artery, with an algorithm proposed for the management. Ann Vasc Dis 2015;8:120-123.

14 Ko SH, Hye R, Frankel DA: Management of spontaneous isolated visceral artery dissection. Ann Vasc Surg 2015;29:470-474. 


\section{Case Reports in Gastroenterology

\begin{tabular}{l|l}
\hline Case Rep Gastroenterol 2016;10:775-780 \\
\hline DOI: 10.1159/000448879 & $\begin{array}{l}\text { C 2 2016 The Author(s). Published by S. Karger AG, Basel } \\
\text { www.karger.com/crg }\end{array}$ \\
\hline
\end{tabular} \\ Nath et al:: Spontaneous Isolated Superior Mesenteric Artery Dissection}

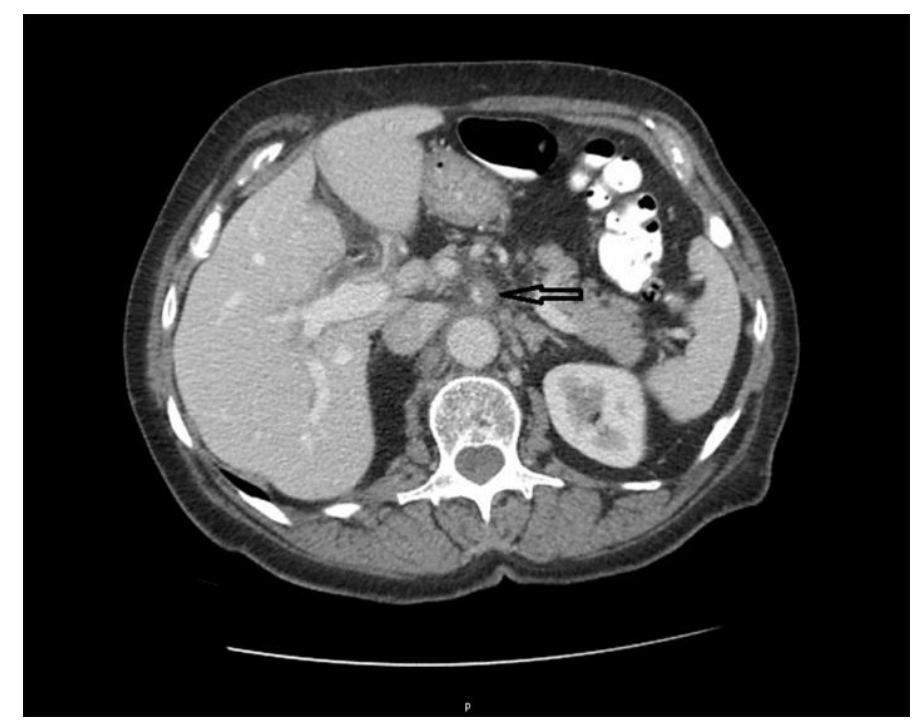

Fig. 1. Cross-sectional view of the isolated SMA dissection (arrow) on CT angiogram.

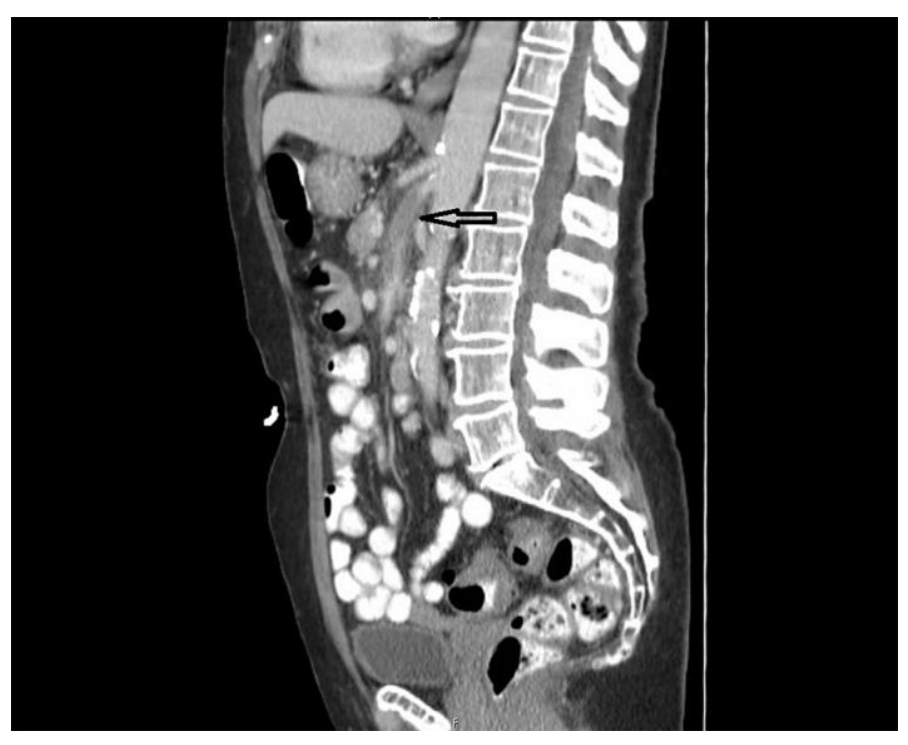

Fig. 2. Sagittal view of the isolated SMA dissection (arrow) on CT angiogram. 


\section{Case Reports in Gastroenterology

\begin{tabular}{l|l}
\hline Case Rep Gastroenterol 2016;10:775-780 \\
\hline DOI: $10.1159 / 000448879$ & $\begin{array}{l}\text { @ 2016 The Author(s). Published by S. Karger AG, Basel } \\
\text { www.karger.com/crg }\end{array}$ \\
\hline
\end{tabular} \\ Nath et al.: Spontaneous Isolated Superior Mesenteric Artery Dissection}

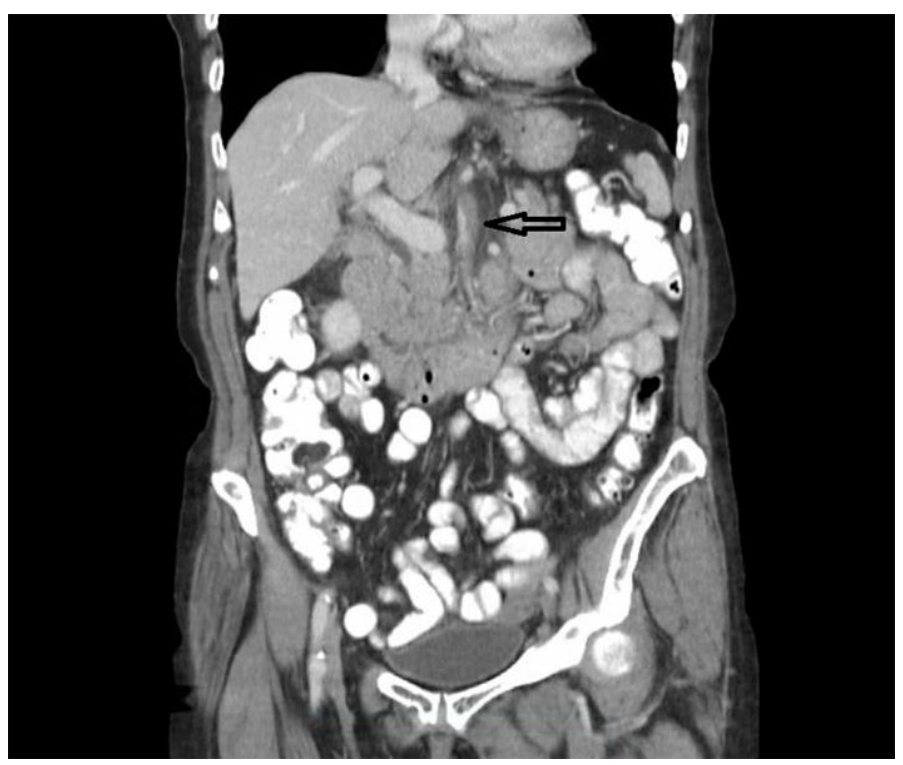

Fig. 3. Coronal view of the isolated SMA dissection (arrow) on CT angiogram. 